Psychological Medicine, 1992, 22, 295-305

Printed in Great Britain

EDITORIAL

\title{
Genetics and developmental stability: an integrative conjecture on aetiology and neurobiology of schizophrenia ${ }^{1}$
}

A number of the aspects of the incidence, symptoms, and accompanying characteristics of schizophrenia are particularly difficult to explain by most current models proposed for the disease. Vulnerability to schizophrenia clearly has a genetic component (Gottesman \& Shields, 1967; Gottesman et al. 1982) but its nature remains unclear. Several different models for the inheritance of developing schizophrenia are proposed by different investigators. For example a general single locus (GSL) is suggested by Meehl (1989) to create, via pre- and post-natal developmental processes, a schizotypal phenotype, which has a certain probability of developing into a clinical schizophrenia. In this scheme, certain core features, seen in neurological soft signs, are evidenced in all individuals with the genotype, regardless of their clinical manifestations. A multifactorial threshold (MFT) basis is an alternative proposed by Gottesman \& Shields $(1967,1972)$ in which a certain number of genetic factors is required in order to cross a threshold for expression of the disorder. Environmental factors (stressors) may move the threshold up or down with respect to the requisite number of genetic factors: unfavourable environments may predispose an individual with a comparatively lower genetic vulnerability to an increased risk of developing schizophrenia. In the MFT model, genetic and environmental factors may work pre-natally and post-natally providing various trajectories for predisposing the individual to schizophrenia. Evidence for prenatal influence of the responsible mechanisms has been presented by Cannon et al. (1989) and challenged by Kendell \& Kemp (1989).

Empirical studies performed to discriminate between proposed genetic mechanisms have thus far been inconclusive. While several recent reports claim to have demonstrated segregation of a single genetic factor (Bassett et al. 1988; Sherrington et al. 1988), other research workers have been unable to replicate this finding (Kennedy et al. 1988; St. Clair et al. 1989; Kaufman, 1989). Epidemiological data (incidence and family data) are still best explained by a MFT model (McGue; et al. 1983; 1985), with the likelihood that segregation at three to four major effect loci is involved (Risch, 1990). A perplexing feature of the disease and one which has confounded conclusive genetic analysis is its tremendous degree of variable expressivity. Individuals may vary with respect to the age of onset, symptomatology, course of illness, responsiveness to chemotherapy, outcome, and performance on neuropsychological tests from normal (Gottesman \& Bertelsen, 1989) to severe and chronic (Bleuler, 1974). Particularly problematic from an aetiological standpoint are the perturbations of functional and structural brain lateralization and symmetry patterns compared to nonschizophrenic control populations (see review by Merrin, 1981; Gruzelier \& Flor-Henry, 1979), as studies are often inconsistent with respect to the existence of an asymmetry disturbance or the side involved. Myslobodsky et al. (1983) summarized studies reporting laterality disturbances in schizophrenia and concluded that it was impossible to find the 'common laterality denominator' in this disorder. However, individual differences in asymmetry patterns, while appearing to defy explanation by a particular aetiological mechanism, may in themselves indicate the action of a single epigenetic process.

Below I describe the concept of developmental stability, its genetic basis, and a model for its potential role in explaining many of the puzzling features of schizophrenia. The model leads to certain predictions for which I provide support from my own research and from published material of other investigators.

\footnotetext{
1 Address for correspondence: Dr Therese Ann Markow, Department of Zoology, Arizona State University, Tempe, Arizona 85287-1501, USA.
} 


\section{WHAT IS DEVELOPMENTAL STABILITY?}

Developmental stability is the ability of an organism properly to execute its ontogenetic programme despite adverse environmental conditions (Waddington, 1957). Both major and minor physical anomalies provide an indication of the presence of disruptive influences during development (Waldrop \& Halvorson, 1971) but their occurrence is usually qualitative and not particularly amenable to multivariate analyses. A useful measure of developmental stability is a phenomenon called fluctuating asymmetry (FAS) easily measured in bilateral morphometric and qualitative traits (Palmer \& Strobeck, 1986).

In order to understand the nature of FAS, other types of naturally occurring asymmetries must be described and compared. One type of assymetry found in bilateral organisms is directional asymmetry (DAS). In DAS, all members of a species show consistent structural or functional bias for a particular side of the body. Examples of DAS include direction of shell coiling in snails, placement of the eyes in flatfish such as flounders, number of lobes in the right $v$. left lung in humans, placement of the heart in humans, and localization of speech to the left hemisphere. Another kind of naturally occurring asymmetry is antisymmetry (AS). Traits showing antisymmetry are consistently exaggerated on one side of the body or the other, but within a population, there is equal probability of it being on the right or left side. In male fiddler crabs, one claw is greatly enlarged and is used in signalling. The enlargement occurs with equal frequency on either side, exemplifying AS.

Fluctuating asymmetry also occurs randomly with respect to right or left side but it is produced when environmental factors interfere with the ability of an organism to execute its developmental plan equally on both sides. Because the degree of interference is variable in FAS, it is distinguished from AS in that distributions of traits showing AS are bimodal or highly platykurtotic compared to the normal distributions of traits showing FAS. Measures of FAS thus reflect the degree to which an organism can buffer itself against a wide range of environmental perturbations and still develop according to its genetically determined plan.

\section{GENETIC BASIS OF DEVELOPMENTAL STABILITY AND FLUCTUATING ASYMMETRY}

Individuals differ in their ability to regulate development homeostatically and this ability has been shown to be a property of the genetic constitution of the organism. The relationship between heterozygosity and developmental stability has been repeatedly demonstrated by empirical studies comparing FAS between organisms with different genotypes (Tebb \& Thoday, 1954; Reeve, 1960; Van Valen, 1962; Bader, 1965). While heterozygosity at single loci may be associated with increased developmental stability and low FAS, this relationship becomes more pronounced as overall genomic levels of homozygosity increase (Mitton \& Grant, 1984; Mitton \& Koehn, 1985). The greater developmental homeostasis of highly heterozygous individuals is apparently due to the presence of more than a single molecular form of a gene product at a given locus, which results in an increased ability to compensate metabolically for a varying environment (Vrijenhoek \& Lerman, 1982; Leary et al. 1983, 1984). The relationship between genotype and FAS thus may be utilized as an index of overall levels of homozygosity present in a species or certain populations of a given species (Leary \& Allendorf 1989).

Certain predictions about the occurrence of FAS in natural populations follow from its relationship to homozygosity. One prediction deals with the association between individuals with extreme phenotypes for continuous traits with a multifactorial-polygenic basis and their relative homozygosity. Examples of such continuous traits in humans include height, weight, and blood pressure. The additive genetic basis of continuous traits is adequately described in genetics textbooks (Vogel \& Motulsky, 1988). Continuous traits are largely influenced by alleles at a larger number of loci acting additively (see Fig. 1). This is a generalization and for some traits, the action of one or more major effect loci appears to be detectable against a polygenic background (Thoday, 
Distribution of trait genotypes

Degres of homozygosity

Degree of developmental stability
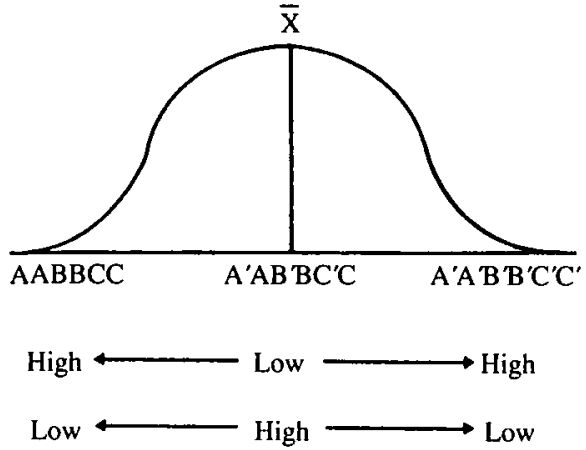

FIG. 1. The relationship between a metric, or continuously distributed phenotype, underlying genotypes, and associated degree of developmental stability. Normal curve reflects a frequency distribution for any continuous trait, such as height, weight, or reaction time. Individuals close to the population average tend to be more heterozygous and exhibit greater developmental stability.

1961 ; Morton \& MacLean, 1974; Lander \& Botstein, 1987). For continuous traits, individuals whose phenotypes lie within the central portion of the distribution tend to be more heterozygous at the responsible loci, while homozygosity increases in extreme phenotypes. This relationship predicts that individuals with extreme phenotypes for continuous traits should also exhibit an increase in developmental instability. The greater developmental stability of the intermediate phenotypes is thus rooted in their heterozygosity and forms the basis of stabilizing selection (Dobzhansky, 1962), via reduced fitness of homozygous genotypes. One continuous trait, birthweight, provides a particularly striking example. The frequency of infant deaths is higher for the lightest as well as the heaviest babies (Karn \& Penrose, 1951). Babies in the intermediate class are considered to be more heterozygous at a large number of loci, thus being favoured by stabilizing natural selection (Cavalli-Sforza \& Bodmer, 1971) or selection against extreme phenotypes. The prediction which follows from this relationship is that individuals whose phenotypes are in the tails of the distribution should to be more homozygous and thus, they should exhibit a higher degree of FAS than individuals with average phenotypes (also shown in Fig. 1).

In humans, anatomical effects of homozygosity have been studied for many years and evidence for a physical manifestation of the homozygous condition have been repeatedly uncovered: for example, in dermatoglyphics (Martin et al. 1982; Soule \& Couzin-Roudy, 1982; Livshitz \& Kobyliansky, 1987), oral and facial clefts (Adams \& Niswander, 1967; Woolf \& Gianas, 1976), and numbers of teeth (Bailit et al. 1970; Townsend \& Brown, 1980; Smith et al. 1983), to name a few. In each of these areas, high levels of homozygosity are associated with an increased level of developmental instability as measured by FAS.

\section{DEVELOPMENTAL STABILITY AND THE CENTRAL NERVOUS SYSTEM}

Neither direct nor indirect effects of homozygosity have been examined with regard to central nervous system (CNS) structure in humans or other mammals. It would be very surprising if homozygosity, while producing developmental instability in the various bilateral traits discussed above, had no influence on the development of the CNS. Neural tissue develops from the same embryonic cell layer that gives rise to teeth and skin, hence nervous tissue must be exposed to environmental regimes similar in variation to those which affect these tissues. The developing CNS should theoretically be subject to the same consequences these tissues are-i.e. deviations from normal or anticipated symmetry or asymmetry under increasing regimes of genomic homozygosity.

It would also be very surprising if these predicted developmental perturbations of CNS structure and chemistry had no influence on the organism's behaviour. If developmental instability can be shown to influence the structural or chemical components of the CNS, the potential link between 
levels of heterozygosity and normal behaviour would be supported. With respect to continuous morphometric traits, the relationship between extreme expression of a trait, homozygosity and reduced fitness has been repeatedly established. Because behaviour lies at the interface between organism and environment, abnormal behavioural phenotypes, associated with homozygosity, may be among the primary factors reducing the fitness of homozygous extremes.

The concept of 'phenodeviance' (Lerner, 1954), or morphological aberrations associated with homozygosity, can be extended to include behavioural phenotypes (Gottesman \& Shields, 1967). Aberrant behaviours, as examples of phenodeviance, would be maladaptive and have the same genetic basis as phenodeviance for morphometric traits, i.e. greater genetic homozygosity. Behaviours, while they are traits characterizing and produced by whole organisms, are rooted in the central nervous system, which is an organ system exhibiting bilateral symmetry. However, in some animals, such as man, the CNS has differentiated in a way that structure and function show speciestypical deviations from bilateral symmetry in one direction or another (Dimond \& Beaumont, 1973; Harnad et al. 1977; Galaburda et al. 1978; Bradshaw \& Nettleton, 1981; Glass, 1984). Lateralization is the functional equivalent of structural directional asymmetry (DAS). The importance of having the normal distribution of physiological and structural processes in the CNS is supported by observations that substantial disturbances in typical lateralized function are frequently associated with psychopathology (Hier et al. 1987, 1979; Rosenberger \& Hier 1980). It is reasonable to expect that disturbances in typical structural or neurochemical features of a developmental origin could have severe consequences for behaviour.

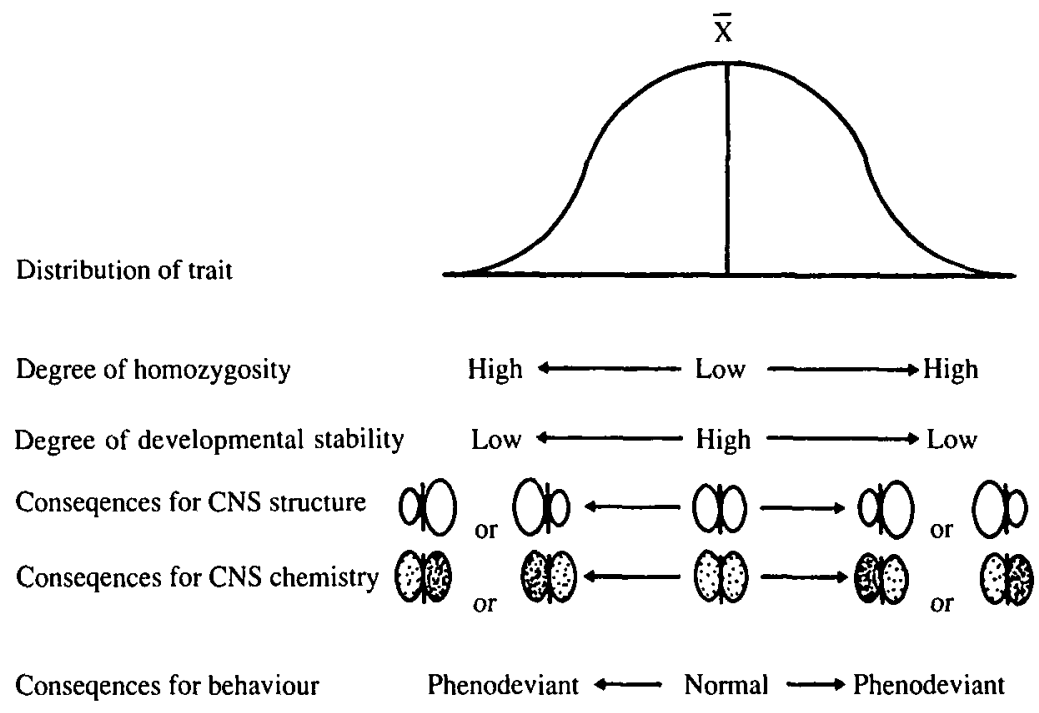

FIG. 2. The relationship between phenotype for a metric or continuous trait, genotype, and developmental stability as manifested in fluctuating asymmetry in the central nervous system (CNS) and behaviour. In this example, for the sake of simplicity, lateralization in the CNS is not presented. The influence of developmental instability on lateralization is presented in Fig. 3.

Fig. 2 presents the general relationship between phenotype, genotype, and developmental stability as it applies to CNS structure, chemistry and behaviour. For any continuous trait, individuals with normal phenotypes (i.e. within 2 standard deviations of the mean) show symmetry in CNS structure and chemistry. They are expected to exhibit normal behaviour. Toward the ends of the distribution, homozygosity increases with concomitant increases in FAS for CNS structural and chemical features. Behaviour is also expected to be more atypical in these individuals.

The human brain is characterized by lateralization of both function and structure, though normal members of the species may exhibit individual variability with respect to hemispheric function and plasticity. Directional asymmetries, such as those found in the human brain, are derived originally 


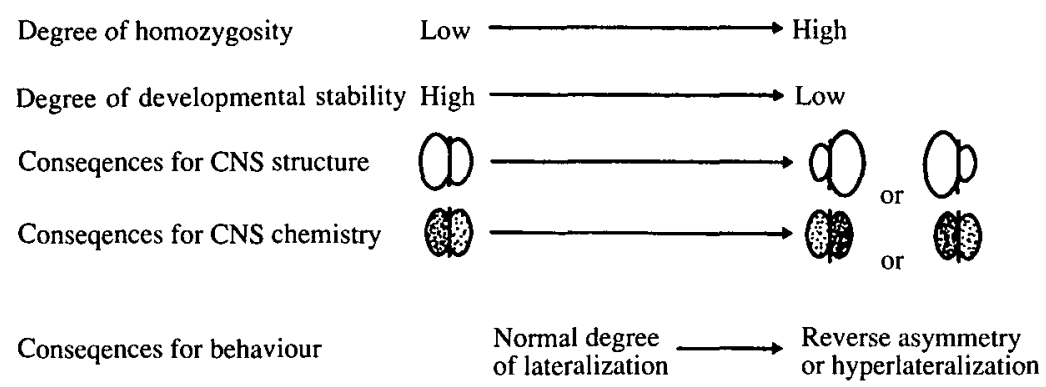

FIG. 3. Influence of developmental stability on lateralized structure and function in the CNS.

from cytoarchitectural differentiation in the oocyte or the environment (see review of maternal effects and asymmetries by Morgan, 1977), rather than by the genotype of the developing individual. Genotypic factors may interfere with development of expected asymmetries but not create them per se. In the case of CNS features which are normally asymmetrical, the expected result of developmental instability is somewhat different (Fig. 3). Increased homozygosity and developmental instability should be associated with an increase in one of two kinds of modification of normal lateralization: reduction or reversal of normal asymmetry pattern or exaggeration of expected degree of asymmetry. Reversals would be more obvious and therefore probably more readily detectable but either of these effects may underlie abnormal behaviour. A CNS with a high degree of structural and functional specialization, as exemplified by lateralization, would be expected to be even more sensitive to the behavioural consequences of developmental instability than a less specialized, symmetrical nervous system.

\section{DEVELOPMENTAL INSTABILITY AND SCHIZOPHRENIA : PREDICTIONS}

Gottesman and associates (Gottesman \& Shields, 1967; Gottesman et al. 1982; McGue et al. 1985) provide a model in which vulnerability to schizophrenia depends upon polygenes acting additively to a threshold for expression of the disorder. Due to variation in dynamic interactions between genotype and environment, trajectories for development of schizophrenia for each individual may vary. An unknown number of loci show specificity for the disease, but across these loci, a minimum number (threshold) of alleles must be present in order for clinical symptoms to be manifested. The model cannot identify the function of each locus but its proponents suggest the likelihood that at least some are involved with neurotransmitter metabolism and function. While environmental stressors have a role in determining how many alleles are required for the threshold to be crossed, in general, homozygosity increases as the trait is expressed. Fig. 4 presents the correlated predictions for severity of a threshold trait, in this case, schizophrenia, that must arise through the mechanisms of pleiotropy. Developmental instability and hence fluctuating asymmetry, are expected to increase as the threshold is reached and surpassed. Thus, in addition to, and superimposed upon, the specific biochemical phenotype created by the responsible genes, developmental instability in various degrees and involving varying anatomical structures in the CNS, adds another, often illusive dimension to the schizophrenia phenotype. In other words, FAS in the brain is not itself a cause of schizophrenia, or else individuals showing developmental instability resulting from other genotypic/environmental factors (cleft lip \pm palate, inbreeding, etc.), would show schizophrenic symptoms. Genes specific for the biochemical lesions in schizophrenia must be present, but in being present in sufficient amounts to create schizophrenic symptoms, there is a concomitant increase in homozygosity and 'systemic' developmental instability.

If this model has validity in explaining some of the structural and functional features of schizophrenia, several predictions can be made. These predictions are listed below and are followed by a discussion of supporting examples. 


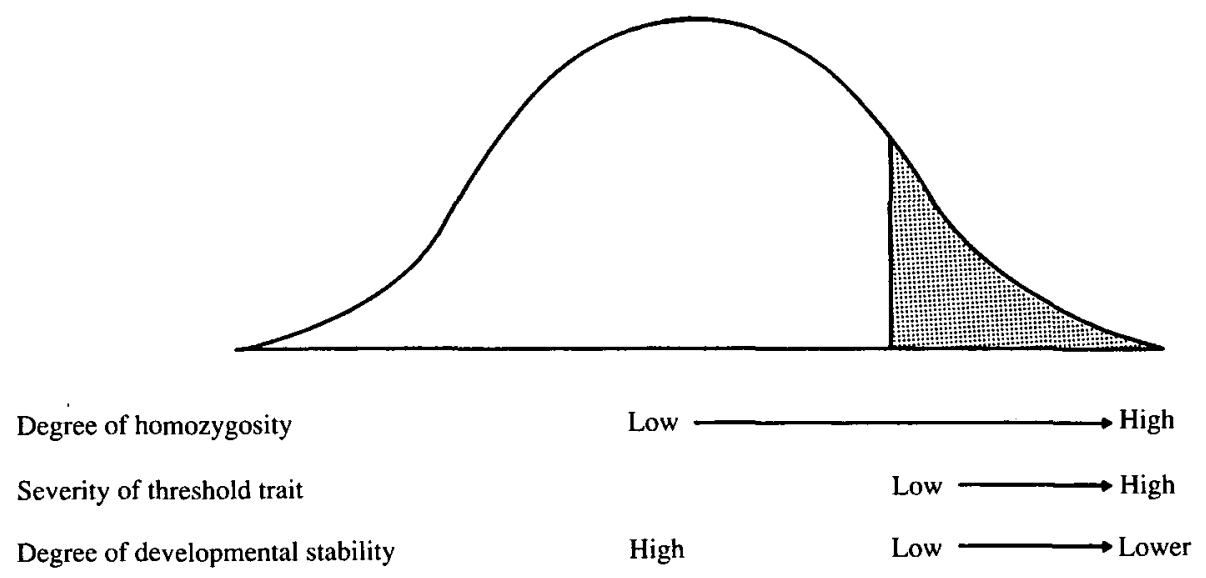

Fig. 4. Predicted relationship between developmental stability and the expression of schizophrenia under a polygenic threshold model.

1. If the genetic basis underlying vulnerability to schizophrenia is polygenic and has a threshold for expression, individuals having the disorder will be more homozygous which should result in increased developmental instability or FAS in bilateral traits.

2. Individuals showing more extreme forms of the disorder (earlier age of onset, poor course of illness) would be expected to have greater genetic predisposition for the disorder and thus exhibit greater developmental instability than less severely affected individuals.

3. Developmental instability may either create asymmetry, or enhance, eliminate or reverse preexisting, normal structural and functional asymmetries in the central nervous system. Because of the random nature of FAS, these asymmetries and reversals, disappearances or enhancements of normal asymmetries will appear to be highly variable and inconsistent between affected people and also between samples of affected people. Behaviours which are lateralized will show increased departures from normal patterns of asymmetries. Departures from normal functional asymmetries will also be variable, and could manifest themselves as problems with interhemispheric integration.

4. Unaffected first-degree relatives of schizophrenics would be expected to show greater tendencies toward developmental instability compared to the general population because of an increased number of the responsible polygenes (and hence increase homozygosity) in these individuals.

\section{TESTING THE PREDICTIONS OF THE MODEL}

1. Increased fluctuating asymmetry and schizophrenia. Utilizing two different dermatoglyphic traits, a-b ridge count and finger-print pattern, Markow \& Wandler (1986) were able to demonstrate that schizophrenic subjects showed significantly greater FAS than either normal subjects or an affective disorder psychiatric control group. The likelihood that manic depression has a different aetiology from schizophrenia is supported by the finding that affective patients showed no evidence of decreased developmental stability, and is consistent with the role of a single major locus underlying some cases of bipolar disorder. Increased FAS in the schizophrenic sample supports the role of polygenes in this disorder. A recent study by Ricker et al. (1989) also showed significantly greater FAS for dermatoglyphic traits in a different sample of schizophrenic subjects.

2. Increased fluctuating asymmetry and severity of schizophrenia. Markow \& Wandler (1986) also looked at the relationship between severity of illness and degree of FAS. One measure of severity examined was age at first hospitalization, which ranged from 11 to 39 . Age at first hospitalization was inversely correlated with FAS in $\mathrm{a}-\mathrm{b}$ ridge count and finger-tip patterns. 
Individuals who were younger when first hospitalized thus exhibited less developmental stability than individuals who had been older. Another measure of severity was course of illness. Patients showing deteriorating course of illness exhibited the greatest FAS.

Following similar reasoning, degree of severity and hence genetic vulnerability was examined in twin pairs concordant $v$. discordant for schizophrenia. Markow \& Gottesman $(1989 b)$ predicted that regardless of zygosity, concordance for schizophrenia should reflect greater genetic liability than discordance and that members of concordant twin pairs should therefore exhibit greater developmental instability or FAS. Using a different dermatoglyphic feature, Absolute Finger Ridge Count (AFRC), concordant and discordant twins originally described by Slater (1953) were compared for degree of FAS. Individuals from twin pairs where both twins were mentally ill (any zygosity) were significantly more asymmetrical than from discordant pairs.

3. Abnormal symmetry patterns and fluctuating asymmetry in the CNS. A large number of investigations report disturbances of CNS symmetries, asymmetries, and lateralized function in schizophrenia (Flor-Henry, 1979; Merrin, 1981; Myslobodsky, 1983; Geschwind \& Galaburda, 1987). The significance of these observations has received a good deal of discussion but remains unanswered. In most reports, data are presented in terms of mean values for left and right structures or characters, whether the trait in question is density from a CT scan (Golden et al. 1981; Largen et al. 1983; Coffman et al. 1984), distribution of neurochemicals (Reynolds, 1983), brain area (Brown et al. 1986), evoked or auditory potentials (Connolly et al. 1983a, b, 1985), rather than right-left (R-L) differences. Without actually determining R-L differences (FAS) and comparing their variances among groups, it is impossible to test the hypothesis that the observed symmetry/asymmetry disturbances represent a decrease in developmental stability.

In a number of reports, however, the data are presented in such a way as to be informative. For example, if brains of schizophrenics show developmental instability, an expected concomitant of FAS would be increased variances for structural measures of both right and left hemispheric regions compared to variances in controls. Golden et al. (1981), report variances for CT densities of different right- and left-brain regions in schizophrenics and normal controls, and in the overwhelming majority of their comparisons, variances are larger for the measures made on schizophrenic brains.

Luchins et al. report asymmetry reversals in frontal (1979) and occipital (1982) regions of schizophrenic brains compared to normal control brains. In the earlier study, normal brains $(N=$ 80) were seen to exhibit larger right sides in $58 \%$ of subjects, no asymmetry in $30 \%$, and left asymmetry in $13 \%$. Among schizophrenics with no brain atrophy $(N=29)$, right frontal asymmetry was seen in $28 \%$ of brains, $21 \%$ were symmetrical, and left asymmetry was seen in $52 \%$. A similar situation appeared for the occipital region (Luchins et al. 1982) in an even larger sample. Of 100 controls, $46 \%$ showed left asymmetry, $49 \%$ were symmetrical, while only $5 \%$ showed right asymmetry. Among schizophrenics without brain atrophy, only $38 \%$ showed left asymmetry, $40 \%$ were symmetrical, and $22 \%$ showed right asymmetry. While these data are not presented in quantitative terms, e.g. actual areas or R-L differences, they are consistent with the prediction in Fig. 4.

One attempt to replicate the foregoing observations was reported to be unsuccessful. Andreasen et al. (1982) used a different method of measuring asymmetry to compare occipital CT dimensions between schizophrenics and normal controls. The interpretation of these findings is complicated by the fact that the numbers and proportions in their tables do not add up to the totals provided.

Perturbations of lateralization in neurochemicals is also predicted by the model. Reynolds et al. (1987) report upon $\mathrm{D}_{2}$ receptor density in post-mortem brain tissue from a small sample. The slight but significant asymmetry, favouring the right putamen, shows both accentuation in schizophrenia as well as one extreme case of asymmetry reversal. An increase in the size of the standard error bars for schizophrenia over controls, despite the comparatively larger sample size, indicates an increased variance as well. While mean right-left differences are not presented, their nature can be inferred from the text and figure of that report and appear to be consistent with an increase in fluctuating 
asymmetry in putamen $\mathrm{D}_{2}$ receptor density. A more recent in vivo study of $\mathrm{D}_{2}$ receptor asymmetry (Farde et al. 1990) does not allow inferences to be made about FAS.

Deviations in functional asymmetry are also predicted from the model and data from several studies are presented in such a way as to be useful in examining these predictions. Connolly et al. (1985) examined event-related potential (ERP) asymmetries with particular reference to contralateral dominance of the N120 peak amplitude. Many patients failed to show the N120 contralateral dominance effect typical of normals and the hemispheric asymmetries observed, whether ipsilaterally or contralaterally dominant, were significantly more exaggerated than controls. An increase in auditory asymmetry reversals, exaggerated asymmetries and elimination of asymmetries can also be supported by the results of language-based dichotic tasks (Lerner et al. 1977; Colbourn \& Lishman, 1979).

A less direct but equally important measure of functional asymmetry is hand preference. Studies of handedness in various populations have been criticized on a number of grounds (Schwartz \& Kirsner, 1984). Nonetheless, an increase in left handedness among psychotic subjects has been reported in several studies (Lishman \& McMeekan, 1976; Taylor et al. 1982). This increase is observed in the absence of family history of sinistrality, suggesting the responsible factors to have been other than a simple genetic basis. The observation is consistent with the influence of some sort of earlier environmental stressors which individuals of the relatively more homozygous genotypes expected with a threshold mode of inheritance for schizophrenia would be less able to buffer than normal controls.

For strongly lateralized traits such as handedness (Levy, 1977) or regional blood flow (Gur \& Reivich 1980), in which most individuals of the population show the same direction of asymmetry, it is particularly difficult to detect deviations other than reversals of normal asymmetries. One reason for this is that measurements tend not to be analysed in ways which permit assessment of hyperlateralization or increases of normal asymmetry as predicted to result from decreased developmental stability. Another potential problem may arise from scale effects, because in asymmetrical traits, the average degree of directional asymmetry (e.g. hemispheric dominance or laterality) for the population may be near the ceiling or limit already. If fluctuating asymmetry shifts function from one hemisphere to the other, it may be interpreted as overactivation or impairment of a specific hemisphere, misleading research workers as to the significance of the hemispheric impairment. For example, Gur et al. (1983) reported that in normal subjects, blood flow to the left hemisphere increased during verbal tasks while no regional increase was detected in schizophrenics. During spatial tasks, blood flow increased to the right hemisphere in normals but was reversed to the left in schizophrenics. Means are reported without any indication of their variances for either group and the data are not presented in a way to reveal what proportion of the patient group actually showed the deviation from the normal pattern. Is it possible that a portion of the schizophrenics showed the same pattern as normals or an increase in the amount of flow to the same regions as normals? In the absence of alternative perspectives, the conclusion that left hemisphere function is specifically impaired was probably the most obvious and attractive one.

In a study of lateralized function in schizophrenia, Gruzelier (1983) provides evidence for two groups of patients, based upon a series of neuropsychological tests. Schizophrenics with acute or reactive symptoms and good prognosis exhibited overactivation of the left and underactivation of the right hemisphere. Poor prognosis with chronic and residual symptoms showed underactivation of the left and overactivation of the right hemispheres. In other words, the first group showed exaggeration of normal functional asymmetry while the second group showed reversal. These observations, along with the others discussed above may represent fluctuating asymmetry in the CNS brought about by developmental instability at much earlier periods.

4. Increased FAS in first degree relatives of subjects with schizophrenia. In the case of at least one trait, cleft lip and without cleft palate $(C L \pm P)$, increased FAS in dermatoglypic traits has been reported in affected individuals and to a lesser but still statistically significant degree in their unaffected first-degree relatives (Woolf \& Gianas, 1977). While no direct tests of FAS in the relatives 
of schizophrenics have been reported, findings of decrements in performance on cognitive tasks (Neuchterlein, 1983) suggest the possibility that other disturbances may be detected as well.

\section{FUTURE TESTS OF THE DEVELOPMENTAL STABILITY MODEL IN SCHIZOPHRENIA}

Schizophrenia is clearly a complex disorder from its aetiology to its symptomatology paralleling such disorders as diabetes and coronary heart diseases. Specific genetic factors and localized neurobiological lesions, while likely to exist, may be lost in a sea of complicated developmental interactions, difficult to tease apart. The concept of fluctuating asymmetry in the CNS is compatible with the suggestion by Weinberger (1987) that the abnormalities in the brains of schizophrenics reflect pathology occurring early in development, with the causative processes possibly differential cell growth, death, neuronal regression or circuitry (Murray et al. 1988) being inactive long before the diagnosis is made. In Weinberger's neurodevelopmental model, a 'lesion early in life' interacts with normal brain maturational events occurring later in life. One 'lesion early in life' may be developmental instability, which, because of its random nature, affects different individuals in different ways, thus accounting for the variability among subjects. This scenario does not preclude the action of a gene or genes with more specific effects (e.g. loci for dopamine metabolism or receptors), acting in conjunction with or superimposed upon the developmentally unstable phenotype created earlier in life.

In order to evaluate the influence of developmental stability in the CNS of schizophrenics, investigators with measurements on structural or functional brain features can re-analyse their observations in ways permitting detection of FAS. New studies concerned with laterality or asymmetries should be designed in ways enabling investigators to test for FAS. Since manifestations of FAS in the brain which are likely to alter behaviour may not necessarily be reflected in gross anatomical measures, investigators should employ techniques which measure function such as PET scans during an array of tasks, and immunohistological procedures which allow quantitative measurement of localized neurochemicals (Farde et al. 1990).

Phenotypic variation in human behaviour, especially when extreme as in psychopathology, can be difficult to understand. However, the genetics, development and behaviour of Homo sapiens are guided by the same principles and processes as in other creatures. Enquiry into the aetiology of schizophrenia should therefore incorporate biological concepts that apply to all organisms.

THERESE ANN MARKOW

Drs Irving Gottesman and Charles Woolf provided helpful comments on earlier drafts of this paper.

This study was conducted while in receipt of NIMH grant no. MH42266.

\section{REFERENCES}

Adams, M. S. \& Niswander, J. D. (1967). Developmental 'noise' and a congenital malformation. Genetical Research 10, 313-317.

Andreasen, N. C., Dennert, J. W., Olson, S. A., \& Damasio, A. R. (1982). Hemispheric asymmetrics and schizophrenia. American Journal of Psychiatry 139, 427-430.

Bader, R. (1965). Fluctuating asymmetry in the dentition of the house mouse. Growth 29, 291-300.

Bailit, H. L., Workman, P. L., Niswander, J. D. \& MacLean, C. J. (1970). Dental asymmetry as an indicator of genetic and environmental conditions in human populations. Human Biology 42, 626-638.

Bassett, A. S., McGilliray, B. C., Jones, B. D. \& Pantzar, J. T. (1988). Partial trisomy chromosome 5 cosegregating with schizophrenia. Lancet i, 799-801.

Bleuler, M. (1974). The longterm cause of the schizophrenic psychoses. Psychological Medicine 4, 244-254.

Bradshaw, J. L. \& Nettleton, N. C. (1981). The nature of hemispheric specialization in man. Behavior and Brain Sciences 4, 51-93.
Brown, R., Colter, N., Corsellis, J. A. N., Crow, T. J., Frith, C. D., Jagoe, X. X. \& Johnstone, E. C. (1984). Post mortem evidence of structural brain changes in schizophrenia. Archives of General Psychiatry 43, 36-42.

Cannon, T. D., Mednick, S. A. \& Parnas, J. (1989). Genetic and perinatal determinants of structural brain deficits in schizophrenia. Archives of General Psychiatry 46, 883-889.

Cavalli-Sforza, L. L. \& Bodmer, W. (1971). The Genetics of Human Populations. W. H. Freeman: San Francisco.

Coffman, J. A., Andreasen, N. C. \& Nasrallah, H. A. (1984). Left hemispheric density deficits in chronic schizophrenia. Biological Psychology 19, 1237-1247.

Colbourn, C. J. \& Lishman, W. A. (1979). Lateralization of function and psychotic illness: a left hemisphere deficit? In Hemisphere Asymmetries of Function in Psychopathology (ed. J. H. Gruzelier and P. Flor-Henry), pp. 539-629. Elsevier: Amsterdam.

Connolly, J. F., Gruzelier, J. H. \& Manchanda, R. (1983a). Electrocortical and perceptual asymmetries in schizophrenia. In 
laterality and Psychopathology (ed. P. Flor-Henry and J. H. Gruzelier), pp. 491-516. Elsevier: Amsterdam.

Connolly, J. F., Gruzelier, J. H., Manchanda, R. \& Hirsch, S. R. $(1983 b)$. Visual evoked potentials in schizophrenia: intensity effects and hemispheric asymmetry. British Journal of Psychiatry 142, 152-155.

Connolly, J. F., Manchanda, R., Gruzelier, J. H. \& Hirsch, S. R. (1985). Pathway and hemispheric differences in the event related potential (ERP) to monaural stimulation: a comparison of schizophrenic patients with normal controls. Biological Psychiatry 20, 293-303.

Dimond, S. J. \& Beamont, J. G. (1973). Differences in vigilance performance of the right and left hemispheres. Cortex 9, 259-265.

Dobzhansky, T. (1962). Mankind Evolving: The Evolution of the Human Species. Yale University Press: New Haven.

Farde, L., Wiesel, F. A., Stone-Elander, S., Hallidin, C., Nordstom, A. C., Hall, H. \& Sedvall, G. (1990). $\mathrm{D}_{2}$ Dopamine receptors in neuroleptic-naive schizophrenic patients: position emission romography study with ["Clraclopride. Archives of General Psychiatry 47, 213-219.

Flor-Henry, P. (1979). Laterality, shifts of cerebral dominance, sinistrality, and psychosis. In Hemisphere Asymmetries of Function in Psychopathology (ed. J. H. Gruzelier, and P. Flor-Henry), pp. 3-20. Elsevier/North Holland: Amsterdam.

Galaburda, A. M., LeMay, M., Kemper, T. L. \& Geschwind, N. (1978). Right left asymmetries in the brain. Science 199, 852-856. Geschwind, N. \& Galaburda, A. M. (1987). Cerebral Lateralization: Biological Mechanisms, Associations and Pathology. MIT Press: Cambridge.

Glass, A. (1984). Individual differences in hemispheric specialization. Nato Advanced Science Institute Series, vol. 130. Pleam: New York.

Golden, C. J., Graber, B., Coffman, J., Berg, R. A., Newlin, D. B., Bloch, S. \& Brogan, D. $(1980 a)$. Brain density deficits in chronic schizophrenia. Psychiatry Research 3, 179-184.

Golden, C. J., Moses, J. A., Jr., Zelazowski, R., Graber, D., Zatz, L. M., Horvath, T. B. \& Berger, P. A. $(1980 b)$. Cerebral ventricular size and neuropsychological impairment in young chronic schizophrenics. Archives of General Psychiatry 37, 619-623.

Golden, C. J., Graber, B., Coffman, J., Berg, R. A., Newlin, D. B. \& Bloch, S. (1981). Structural brain deficits in schizophrenia: identification by computed tomographic scan density measurements. Archives of General Psychiatry 38, 1014-1017.

Gottesman, I. I. \& Bertelson, A. (1989). Confirming unexpressed genotypes for schizophrenia. Archives of General Psychiatry 46, 867-872.

Gottesman, I. I. \& Shields, J. (1967). A polygenic theory of schizophrenia. Proceedings of the National Academy of Sciences of the United States of America 58, 199-205.

Gottesman, I. I. \& Shields, J. (1972). Schizophrenia and Genetics: A Twin Study Vantage Point. Academic Press: New York.

Gottesman, I. I., Shields, J. \& Hanson, D. (1982). Schizophrenia: The Epigenetic Puzzle. Cambridge University Press: New York.

Gruzelier, J. (1983). A critical assessment and interpretation of lateral asymmetries in schizophrenia. In Hemisyndromes: Psychobiology, Neurology, and Psychiatry (ed. M. Myslobodsky), pp. 265-320. Academic Press: New York.

Gruzelier, J. H. \& Flor-Henry, P. (eds) (1979). Hemisphere Asymmetries of Function in Psychopathology. Elsevier: Amsterdam.

Gur, R. C. \& Rejvich, M. (1980). Cognitive task effects on hemispheric blood flow in humans: evidence for individual differences in hemispheric activations. Brain and Language 9, 7-92.

Gur, R. E., Skolnick, B. E., Gur, R. C., Caroff, S., Rieger, W., Obrist, W. D., Younkin, D. \& Reivich, M. (1983). Brain function in psychiatric disorder. I. Regional cerebral blood flow in medicated schizophrenics. Archives of General Psychiatry 40, 1250-1254.

Harnad, S., Doty, R. W., Goldstein, L., Jaynes, J. \& Krauthamer, G. (eds) (1977). Lateralization in the Nervous System. Academic Press: New York.

Hier, D. B., LeMay, M. \& Rosenberger, P. B. (1978). Perto-VP: developmental dyslexia. Evidence for a subgroup with a reversal of cerebral asymmetry. Archives of Neurology 35, 90-92.
Hier, D. B., LeMay, M. \& Rosenberger, P. B. (1979). Autism and unfavorable left-right asymmetries of the brain. Journal of Autism Development and Discord 9, 153-159.

Karn, M. N. \& Penrose, L. S. (1951). Birthweight and gestation time in relation to maternal age, parity, and infant survival. Annals of Eugenics 15, 206-233.

Kaufmann, C. A., DeLisi, L., Lehner, T. \& Gilliam, T. C. (1989). Physical mapping, linkage analysis of a putative schizophrenia locus on chromosome $5_{0}$. Schizophrenia Bulletin 15, 441-452.

Kendell, R. E. \& Kemp, I. W. (1989). Maternal influenza in the etiology of schizophrenia. Archives of General Psychiatry 46, 878-882.

Kennedy, J. L., Giuffra, L. A., Moises, H. W., Cavalli-Sforza, L. L., Pakstis, A. J., Kidd, J. R., Castiglione, C. M., Sjogren, B., Wetterberg, L. \& Kidd, K. K. (1988). Evidence against linkage of schizophrenia to markers on chromosome 5 in a northern Swedish pedigree. Nature 336, 167-170.

Lander, E. S. \& Botstein, D. (1987). Homozygosity mapping: a way to map human recessive traits with DNA from inbred children. Science 236, 1567-1570.

Largern, J. W., Jr., Calderon, M. \& Smith, R. C. (1983). Asymmetries in the densities of white and grey matter in the brains of schizophrenic patients. American Journal of Psychiatry 140, 1060-1062.

Leary, R. F. \& Allendorf, F. W. (1989). Fluctuating asymmetry as an indicator of stress: implications for conservation biology. Trends in Ecology and Evolution 4, 213-217.

Leary, F. R., Allendorf, F. W. \& Knudsen, K. L. (1983). Developmental stability and enzyme heterozygosity in rainbrow trout. Nature 301, 71-72.

Leary, F. R., Allendorf, F. W. \& Knudsen, K. L. (1984). Superior developmental stability of heterozygotes at enzyme loci in salmonid fishes. American Naturalist 124, 540-551.

Lerner, I. M. (1954). Genetic Homeostasis. John Wiley \& Sons: New York.

Lerner, J., Naschon, I. \& Carmon, A. (1977). Response of paranoid and nonparanoid schizophrenics in a dichotic listening task. Journal of Nervous and Mental Disease 164, 247-252.

Levy, J. (1977). The origins of lateral asymmetry. In Lateralization in the Nervous System (ed. S. Harnad, R. W. Dotz, L. Goldstein J. Jaynes and G. Krauthamer), pp. 195-209. Academic Press: New York.

Lishman, W. A. \& McMeekan, E. R. L. (1976). Hand preference patterns in psychiatric patients. British Journal of Psychiatry 129, 158-166.

Lishman, W. A., Toone, B. K., Colburn, C. J., McMeekan, E. R. L. \& Mance, R. M. (1978). Dichotic listening in psychotic patients. British Journal of Psychiatry 132, 333-341.

Livshitz, G. \& Kobylianski, E. (1987). Dermatoglyphic traits as possible markers of developmental processes in humans. American Journal of Medical Genetics 26, 111-112.

Luchins, D. J., Weinberger, D. R. \& Wyatt, R. J. (1979). Schizophrenia: evidence of a subgroup with reversed cerebral asymmetry. Archives of General Psychiatry 36, 1309-1311.

Luchins, D. J., Weinberger, D. R. \& Wyatt, R. J. (1982). Schizophrenia and cerebral asymmetry detected by computer tomography. American Journal of Psychiatry 139, 753-757.

McGue, M., Gottesman, I. I. \& Rao, D. E. (1983). The transmission of schizophrenia under a multifactorial threshold, model. American Journal of Human Genetics, 35, 1161.

McGue, M., Gottesman, I. I/ \& Rao, D. E. (1985). Resolving genetic models for the transmissioh of schizophrenia. Genetic Epidemiology 2, 99-110.

Markow, T. \& Gottesman, I. I. (1989a). Fluctuating dermatoglyphic asymmetry in twins and singletons. Hereditas 110, 211-215.

Markow, T. \& Gottesman, I. I. (1989b). Dermatoglyphic fluctuating asymmetry in psychotic twins. Psychiatry Research 29, 37-43.

Markow, T. \& Wandler, K. (1986). Fluctuating dermatoglyphic asymmetry and the genetics of liability to schizophrenia. Psychiatry Research 19, 323-328.

Marsh, L. (1986). Postmortem evidence of structural brain changes in schizophrenia. Archives of General Psychiatry 43, 36-42. 
Martin, N. G., Jinks, J. L., Berry, H. S. \& Loesh, D. (1982). A genetic analysis of directly and asymmetry in finger ridge counts. Heredity 48, 393-405.

Meehl, P. (1989). Schizotaxia revisited. Archives of General Psychiatry 46, $935-944$.

Merrin, E. L. (1981). Schizophrenia and brain asymmetry: an evaluation of evidence for dominant lobe dysfunction. Journal of Nervous and Mental Disease 169, 405-416.

Mitton, J. B. \& Grant, M. C. (1984). Associations among protein heterozygosity, growth rate, and developmental homeostasis. Annual Review of Ecology and Systematics 14, 479-499.

Mitton, J. B. \& Koehn, R. K. (1985). Shell shape variation in the blue mussel, Mytilus edulis $L$. and its association with enzyme heterozygosity. Journal of Experimental Marine Biology and Ecology 90, 73-80.

Morgan, M. (1977). Embryology and inheritance of assymetry. In Lateralization in the Nervous System (ed. S. Harnad, R. W. Dotz, L. Goldstein, J. Jaynes and G. Krauthamer), pp. 173-194. Academic Press: New York.

Morton, N. E. \& MacLean, C. J. (1974). Analysis of family resemblance. III Complex segregation analysis of quantitative traits. American Journal of Human Genetics 26, 489-503.

Murray, R. M., Lewis, S. W., Owen, M. J. \& Forester, A. (1988). The neurodevelopmental origins of dementia praecox. Schizophrenia, the Major Issues. (ed. P. Bebbington and P. McGuffin), pp. 91-106. Heinemann: Oxford.

Myslobodsky, M. S. (1983). Hemisyndromes: Psychobiology, Neurology, Psychiatry. Academic Press: New York.

Myslobodsky, M.S., Mintz, M. \& Tomer, R. (1983). Neuroleptic effects and the site of abnormality in schizophrenia. In Hemisyndromes: Psychobiology, Neurology and Psychiatry (ed. M. S. Myslobodsky), pp. 347-388. Academic Press: New York.

Neuchterlein, K. H. (1983). Signal detection in vigilance tasks and behavioral attributes among offspring of schizophrenic mothers and among hyperactive children. Journal of Abnormal Psychology 92, 4-28.

Palmer, R, \& Strobeck, C. (1986). Fluctuating asymmetry; measurement, analysis, patterns. Annual Review of Ecology and Systematics $17,39 \mid-421$.

Reeve, E. C. R. (1960). Some genetic tests on asymmetry of sternopleural chaetae number in Drosophila. Genetical Research 1 , 151-172.

Reynolds, G. P. (1983). Increased concentrations and lateral asymmetry of amygdala dopamine in schizophrenia. Nature 305, 527-530.

Reynolds, G. P., Czudek, C., Browej, N. \& Seeman, P. (1987). Dopamine receptor asymmetry in schizophrenia. Lancet $\mathbf{i}$, 1710-1716.

Ricker, J. P., Boring, R. H., Harris, A. E. \& Markow, T. (1989). Fluctuating dermatoglyphic asymmetry and its association with positive and negative symptoms in schizophrenia. Schizophrenia Research 2, 73.

Risch, N. (1990). Linkage strategies for genetically complex traits. I. Multilocus models. American Journal of Human Genetics 46, 222-228.

Rosenberger, P. B., Hier, D. B. (1980). Cerebral asymmetry and verbal intellectual deficits. Annals of Neurology 8, 300-304.

Schwartz, S. \& Kirsner, K. (1984). Can group differences in hemispheric asymmetry be inferred from behavioral laterality indices? Brain and Cognition 3, 57-70.

Schweitzer, L., Becker, E. \& Welsh, H. (1978). Abnormalities of cerebral lateralization in schizophrenic patients. Archives of General Psychiatry 35, 982-985.

Sherrington, R., Brynjolfsson, J., Petursson, H., Potter, M. Dudleston, K., Barraclough, B., Wasmuth, J., Dobbs, M. \& Gurling, M. (1988). Localization of a susceptibility locus for schizophrenia on chromosome 5. Nature 336, 164-167.

Slater, E. (1983). Psychotic and Neurotic Illness in Twins. Medical Research Council Special Reports Series No. 278. Her Majesty's Stationery Office: London.

Smith, B. H., Garn, S. \& Cole, P. M. (1983). Problems of sampling and inference in the study of fluctuating dental asymmetry. American Journal of Physical Anthropology 58, 281-289.

Soule, M. E. \& Couzin-Roudy, J. (1982). Allometric variation. 2. Developmental instability of extreme phenotypes. American Naturalist 120, 765-786

St. Clair, D., Blackwood, D., Muir, W., Baillie, D., Hubbard, A., Wright, A. \& Evans, H. J. (1989). No linking of chromosome 5 q11-q13 markers to schizophrenia in Scottish families. Nature 339, 305-309.

Taylor, P. J., Dalton, R., Fleminger, J. J. \& Lishman, W. A. (1982). Differences in two studies of hand preference in psychiatric patients. British Journal of Psychiatry 140, 167-173.

Tebb, G. \& Thoday, J. M. (1954). Stability in development and relational balance of $\mathrm{X}$-chromosomes in $D$. melanogaster. Nature $174,1109$.

Thoday, J. M. (1961). Location of polygenes. Nature 191, 368-370.

Townsend, G. C. \& Brown, T. (1980). Dental asymmetry in Australian aboriginals. Human Biology 52, 661-673.

Van Valen, L. (1962). A study of fluctuating asymmetry. Evolution $16,125-000$.

Vogel, F. \& Motulsky, A. G. (1988). Human Genetics, Problems and Approaches. Springer-Verlag: New York.

Vrijenhoek, R. C. \& Lerman, S. (1982). Heterozygosity and developmental stability under sexual and asexual breeding systems. Evolution 36, 768-776.

Waddington, C. H. (1957). The Strategy of the Genes. Macmillan : New York.

Waldrop, M. \& Halvoroson, C. (1971). Minor physical anomalies: Their incidence and relation to behavior in a normal and deviant sample. In Readings in Development and Relationships (ed. R. Smart, Jr. and M. Smart), Macmillan: New York.

Weinberger, D. R. (1987). Implications of normal brain development for the pathogenesis of schizophrenia. Archives of General Psychiatry 44, 660-669.

Weinberger, D. R. \& Wyatt, R. J. (1982). Brain morphology in schizophrenia: In vivo studies. In Schizophrenia as a Brain Disease (ed. F. A. Henn and H. A. Nasrallah), pp. 148-175. Oxford University Press: New York.

Woolf, C. M. \& Gianas, A. (1976). Congenital cleft lip and fluctuating dermatoglyphic asymmetry. American Journal of Human Genetics 28, 400-403.

Woolf, C. M. \& Gianas, A. (1977). A study of fluctuating dermatoglyphic asymmetry in the sibs and parents of cleft lip propositi. American Journal of Human Genetics 28, 503-507. 